\title{
The future of dentistry: How will personalized medicine affect orthodontic treatment?
}

Gustavo Zanardi', William R. Proffit ${ }^{2}$, Sylvia A. Frazier-Bowers ${ }^{3}$

Scientists are rapidly developing and employing diagnostic tests in medical diagnosis based on genomic, proteomics and metabolomics to better predict the patients' responses to targeted therapy. This field termed 'personalized medicine' combines human genome, information technology, and biotechnology with nanotechnology to provide treatment based on individual variation versus population trends. ${ }^{1,2}$ Similarly, within the last 30 years, orthodontists have seen the introduction of modern appliance designs, digital records, advanced imaging capabilities, and the integration of soft tissue esthetics into diagnosis and treatment planning. It is relatively easy to see how these introductions have advanced the specialty. However, when considering the influence of genetics on contemporary orthodontics, the advances are perhaps not as obvious. The views presented here are based on the central tenet that applying genetic knowledge to the field of orthodontics will augment the current differential diagnosis of malocclusion, permitting recognition of different types of malocclusion that are etiologically discrete and so might respond to treatment in different ways.

\footnotetext{
${ }^{1}$ MSc and Specialist in Orthodontics, Rio de Janeiro State University. Private Practice in Balneário Camboriú, Santa Catarina, Brasil.

${ }^{2}$ Kenan Distinguished Professor, Department of Orthodontics. School of Dentistry, University of North Carolina at Chapel Hill, Chapel Hill, NC, USA.

${ }^{3}$ Associate Professor, Department of Orthodontics. School of Dentistry, University of North Carolina at Chapel Hill, Chapel Hill, NC, USA.
}

This would undoubtedly change the way clinicians choose therapeutic modalities in the future.

The significance of genetics in malocclusion has been known for centuries and has always been a topic of great debate and some controversy. Lundstrom $^{3}$ and others ${ }^{4-10}$ examined the question of 'nature versus nurture' and found that both influenced the development of malocclusion to some extent, with genetics accounting for up to $50 \%$ of malocclusion. In a recent study, Normando et $\mathrm{al}^{11}$ suggested that genetics plays the most important role and prevails over environment on dental malocclusion etiology. Those findings, however, were different from many studies of European-derived population groups. Regardless of whether an environmental versus genetic component prevails, as a result of the Human Genome Project we have witnessed an explosion of molecular advances that is influencing a paradigm shift toward a genetic etiology for many developmental problems, including those that are craniofacial. In this article, we will explore the relationship between genetics and malocclusion from both the historical and contemporary perspectives.

\footnotetext{
How to cite this article: Zanardi G, Proffit WR, Frazier-Bowers SA. The future of dentistry: How will personalized medicine affect orthodontic treatment? Dental Press J Orthod. 2012 May-June;17(3):3-6.

Submitted: April 2, 2012 - Revised and accepted: April 13, 2012

" The authors report no commercial, proprietary, or financial interest in the products or companies described in this article.

Contact address: Gustavo Zanardi

Av. Brasil 177, apto. 2302, ed. Luz do Mar, Centro - Balneário Camboriú / SC, Brazil Zip code: 88.330-040 - Email: gugazanardi@hotmail.com
} 


\section{FUTURE DIRECTIONS IN CLINICAL ORTHODONTICS AND GENETICS}

Currently the diagnosis and treatment of most types of malocclusion is fraught with inconsistencies concerning the timing, duration and type of treatment. For example, the decision of whether to treat early a patient with Class III malocclusion, with growth modification, camouflage orthodontically or prescribe a surgical approach can often present a dilemma for both the clinician and patient. The appropriate choice of treatment is often limited by the specific 'subtype' of Class III malocclusion presented, with reverse pull headgear or a chin cup being contraindicated in certain patients. Therefore, the first and most critical step in the application of genetics to clinical orthodontics must be to develop a comprehensive and detailed phenotypic categorization, which can subsequently be correlated with results from genotyping experiments.

Within the spectrum of orthodontic problems that are suspected to have a genetic etiology, Class III malocclusion provides a good example of a malocclusion that orthodontists acknowledge as genetic in origin. However, the knowledge that Class III malocclusions in many cases possess a genetic etiology does not lessen the challenge in diagnosis and treatment planning. The questions of 'when and how' to treat are still problematic. This is due in part to a more general problem in clinical orthodontics; specifically that much of the diagnostic process, particularly that based on cephalometric analysis is quite controversial. ${ }^{12}$ To address some of the gaps in knowledge and understanding, one attractive proposal would be to develop a system whereby an objective and detailed characterization of malocclusion into specific subtypes (beyond Angle's classification) that could be correlated with specific haplotypes. Using Class III malocclusion as a model for this exercise, the range of the Class III phenotype should be carefully characterized first delineating, for example, between individuals with a Class III relationship as measured by some antero-posterior (AP) determinants such as ANB and overjet, versus those who have a vertical component, such as downward and backward rotation of the mandible masking the AP problem. Clearly many different subtypes exist and may include variation in location and severity of the component distortions. Once these 'subtypes' of Class III can be fully characterized they can then be compiled to determine how the phenotypic subtypes (sub-phenotypes) are inherited within families.

The question is: 'Is there a gene for mandibular prognathism?' Almost certainly multiple genes interact in the development of this condition, just as they do for other aspects of growth. Studies have shown that discrete genetic locations are associated with Class III malocclusion, specifically mandibular prognathism ${ }^{13}$ and maxillary deficiency. ${ }^{14}$ Another more recent study ${ }^{15}$ found that a genetic variation of the protein Myosin (Type I) contributes to mandibular prognathism, which suggests that muscle function might have a more important role than previously thought in the development and deviations of the bone structures of the craniofacial complex. In addition, it is quite likely that the expression of genes is different depending on the subtype of this problem. Today's researchers have at their disposal many techniques to successfully map genes, and the success of these methods in identifying the genetic basis of congenitally missing teeth is impressive. ${ }^{16}$ A similar strategy can be applied toward unraveling the genetic basis of mandibular prognathism. Mouse studies already have shown that distinct quantitative trait loci (QTL) determine the shape of the mandible. ${ }^{17}$ As it becomes clearer what genes are involved in excessive mandibular growth, it is highly likely that genetic analysis will contribute to our knowledge of how to manage this problem. Knowledge of the type of craniofacial growth associated with specific genetic variations could help greatly with both the type and timing of orthodontic and surgical treatment. ${ }^{18}$

Studies in tooth eruption also provide compelling evidence of a genetic etiology in malocclusion, specifically eruption disorders. Molecular studies have revealed that eruption is in fact, a tightly coordinated process, regulated by a series of signaling events between the dental follicle and the alveolar bone. ${ }^{19}$ A disruption in this process can occur as part of a syndrome or as a non-syndromic disorder (isolated or familial) ranging from delayed eruption $^{20}$ to a complete failure of the primary eruption 
mechanism itself. ${ }^{21,22}$ Recently, reports of genetic alterations in the parathyroid hormone receptor 1 (PTH1R) gene ${ }^{19,23}$ further confirmed the molecular basis of tooth eruption; a mutation in the PTH1R gene results in a striking failure of eruption that is hereditary (typically observed as a posterior lateral open bite). This finding is significant for many reasons including: (1) as non-syndromic eruption disturbances are difficult to distinguish from one another (i.e. ankylosis versus PFE or primary retention versus PFE), the knowledge of a genetic cause for some eruption disturbances will undoubtedly help delineate between the diagnoses of eruption disorders stemming from a local versus systemic cause; and (2) establishment of a genetic cause for eruption problems will facilitate a more accurate diagnosis and hence appropriate clinical management of the problem. That is, awareness of an eruption failure due to a genetic mutation in a given patient is certainly an indication that treatment with a continuous archwire should be avoided, as it will only worsen the lateral open bite. ${ }^{22}$

The deciphering and analysis of the human genome signal the inception of a new era of genebased medicine. During the next several decades, many of the current materials and methods may be abandoned in favor of emerging bioengineered technologies, genetically programmed for the prevention and treatment of oral disease as well as for the repair of damaged dental tissues. The development and implementation of these innovative dental therapies will require intensive education of current practitioners. Considerable restructuring of dental school curricula will need to take place, and the emergence of a new dental specialty is anticipated. ${ }^{24}$ Keys to successful treatment outcomes include knowing how different patients respond to various treatment modalities, and how the natural history of many skeletal and connective tissue disorders impact short and long-term orthodontic treatment outcomes. In the more distant future, linkage studies that lead to the identification of specific genetic mutations responsible for certain malocclusion will form the basis for future studies that create specific drug targets to correct discrepancies in facial growth. With the rapid progress made in human molecular genetics and the knowledge gained from the HapMap and Human Genome Projects, we can envision a time when specific haplotypes are linked to distinct sub-phenotypes such as those seen in Class III malocclusion. If we can successfully categorize individuals based on subtypes, then we can start to propose sensible experiments or clinical trials to identify appropriately targeted clinical treatment (i.e. personalized medicine in orthodontics). Further, genetic screening tools whereby a saliva or buccal cell (cheek swab) sample is taken at the initial records visit can be used for diagnosis and to predict predispositions to iatrogenic consequences in patients. In any case, as the field of orthodontics continues to develop technologically and philosophically, we can expect that advances in diagnosis and treatment planning are eminent and inevitable. 


\section{REFERENCES}

1. Hamburg MA, Collins FS. The path to personalized medicine. N EngI J Med. 2010 Jul 22;363(4):301-4

2. Slavkin HC. The human genome, implications for oral health and diseases, and dental education. J Dent Educ. 2001 May;65(5):463-79.

3. Lundström A. Nature versus nurture in dento-facial variation. Eur J Orthod. 1984 May;6(2):77-91.

4. Corruccini RS, Sharma K, Potter RH. Comparative genetic variance and heritability of dental occlusal variables in U.S. and Northwest Indian twins. Am J Phys Anthropol. 1986 Jul;70(3):293-9.

5. Harris EF, Smith RJ. A study of occlusion and arch widths in families. Am J Orthod. 1980 Aug;78(2):155-63.

6. Garib DG, Alencar BM, Ferreira FV, Ozawa TO. Anomalias dentárias associadas: 0 ortodontista decodificando a genética que rege os distúrbios de desenvolvimento dentário. Dental Press J Orthod. 2010 Mar-Apr;15(2):138-57.

7. Consolaro A, Consolaro RB, Martins-Ortiz MF, Freitas PZ. Conceitos de genética e hereditariedade aplicados à compreensão das reabsorções dentárias durante a movimentação ortodôntica. Rev Dent Press Ortodon Ortop Facial. 2004 MarAbr;9(2):79-94.

8. Silva AA. Estudo sobre o crescimento e desenvolvimento craniofacial: teste de associação entre marcadores genéticos e indicadores morfológicos numa amostra de fissurados labiopalatais do estado do Paraná - Brasil. Rev Dent Press Ortodon Ortop Facial. 2007 Jan-Fev;12(1):102-9.

9. Cruz RM, Oliveira, SF. Análise genética de problemas craniofaciais: revisão da literatura e diretrizes para investigações clínico-laboratoriais (parte 1). Rev Dent Press Ortodon Ortop Facial. 2007 Set-Out;12(5):133-40.

10. Cruz RM, Oliveira, SF. Análise genética de problemas craniofaciais: revisão da literatura e diretrizes para investigações clínico-laboratoriais (parte 2). Rev Dent Press Ortodon Ortop Facial. 2007 Set-Out;12(5):141-50.

11. Normando D, Faber J, Guerreiro JF, Abdo Quintão CC. Dental occlusion in a split Amazon indigenous population: genetics prevails over environment. PLoS ONE 2011;6(12):e28387. doi:10.1371/journal.pone.0028387

12. Proffit WR, White RP, Sarver D. Contemporary treatment of dentofacial deformity. St. Louis (Mo): CV Mosby; 2003.
13. Yamaguchi T, Park SB, Narita A, Maki K, Inoue I. Genome-wide linkage analysis of mandibular prognathism in Korean and Japanese patients. J Dent Res. 2005 Mar;84(3):255-9.

14. Frazier-Bowers S, Rincon-Rodriguez R, Zhou J, Alexander K, Lange E. Evidence of linkage in a Hspanic cohort with a class III dentofacial phenotype. J Dent Res. 2009 Jan;88(1):56-60.

15. Tassopoulou-Fishell M, Deeley K, Harvey EM, Sciote J, Vieira AR. Genetic variation in Myosin $1 \mathrm{H}$ contributes to mandibular prognathism. Am J Orthod Dentofacial Orthop. 2012 Jan;141(1):51-9.

16. Stockton DW, Das P, Goldenberg M, D'Souza RN, Patel PI. Mutation of PAX9 is associated with oligodontia. Nat Genet. 2000 Jan;24(1):18-9.

17. Klingenberg CP, Leamy LJ, Cheverud JM. Integration and modularity of quantitative trait locus effects on geometric shape in the mouse mandible. Genetics. 2004 Apr;166(4):1909-21.

18. Proffit WR, Fields HW Jr, Sarver D. Contemporary orthodontics. 4th ed. St. Louis (MO): Mosby Year Book; 2007.

19. Wise GE, King GJ. Mechanisms of tooth eruption and orthodontic tooth movement. J Dent Res. 2008 May;87(5):414-34.

20. Suri L, Gagari E, Vastardis H. Delayed tooth eruption: Pathogenesis, diagnosis, and treatment. A literature review. Am J Orthod Dentofacial Orthop. 2004 Oct;126(4):432-45.

21. Proffit WR, Vig KW. Primary failure of eruption: a possible cause of posterior openbite. Am J Orthod. 1981 Aug;80(2):173-90.

22. Frazier-Bowers SA, Koehler KE, Ackerman JL, Proffit WR. Primary failure of eruption: further characterization of a rare eruption disorder. Am J Orthod Dentofacial Orthop. 2007 May;131(5):578.e1-11.

23. Decker E, Stellzig-Eisenhauer A, Fiebig BS, Rau C, Kress W, Saar K, et al. PTHR1 loss-of-function mutations in familial, nonsyndromic primary failure of tooth eruption. Am J Hum Genet. 2008 Dec;83(6):781-6.

24. Yeager AL. Where will the genome lead us? Dentistry in the 21st century. J Am Dent Assoc. 2001 Jun;132(6):801-7. 